\title{
DYNAMICS OF NONLINEAR AND DISORDERED SYSTEMS
}




\title{
WORLD SCIENTIFIC SERIES ON NONLINEAR SCIENCE
}

\section{Editor. Leon O. Chua}

University of Califomia, Berkeley

\author{
Sortw A. MONOGRAPHS AND TREATISES \\ Volume 1: From Order to Chacs \\ L.P. Kadanoff \\ Volume 2: Ideal Turbutence \\ A. N. Shartovaty, E. YU. Aomenento, and M. B. Vereding
}

Volumo 3: Dynamics of Pieconwer-Monotono Mape
A. N. Sherkovesy, S. F. Kolyade, and A. G. Strak

Volume 4: Qunleattro Tooks of Nonlinear Dynamica

Part 1: Local and Global Blturcations

L. O. Chua, A. L Shifnikov, L. P. Shirnikov, and D. V. Turaev

Volumo 5: Qualitative Toots of Nonlinear Dynamics

Part 2: Homoctinic Chaces

L. O. Chua, A. L. Shifrikov, L. P. Shlinkov, and D. V. Turnov

Volume 6: Stability. Structures and Chaos in Nonlinear Synchronization Networks

V. S. Afreimovich, V. I. Nakorkin, G. V. Osipov, and V. D. Shalleev

Edited by A. V. Gaponov-Greltiov and M. I. Rabinovich

Volume 7: Smooth Imvariant Manifolds and Normal Forms

I. U. Bronstoin and A. Ya. Kopanskt"

Volume 8: Dynarnical Chacs: Models, Experiments, and Applications

V. S. Anishathonko

Volume 9: Frequency Domain Methods for Nonlinear Analysis: Theory and Applications

G. A. Loonov, D. V. Ponomarenko, and V. B. Smimova

Volume 10: Critical Phenomena and Aoads to Chaos in Muttuparameter and Muttidimensional Nonlinear Systems

A. P. Kunnetsov, S. P. Kurnetsov, and I. R. Saterev

Volume 11: Nonllnear Dynamics of Interacting Populations

A. D. Bazyidn

Volume 12: Attractors of Quasiperiodically Forced Systems

T. Kepitaniak and J. Wojowoda

Sorive B. SPECINL THEME ISSUES AND PROCEEDINGS

Volume 1: Chua's Circult: A Paradigm for Chace

Edited by R. N. Madan

Volume 2: Complexty and Chaos

Edited by N. B. Abraham, A. M. Abano, A. Passamanto, P. E. Rapp, and R. Gilmoro

Volume 3: Now Tronds in Pattem Fomation in Active Nonlinear Media

Edited by V. Peraz-Villar, V. Peraz-Munuzur, C. Poraz Garcia, and V. I. Krinsky

Volume 4: Chaos and Nonlinear Mectranics

Edited by T. Kaptaniak and J. Brindloy

Votume 5: Fluid Physics - Lecture Notes of Summer Schools

Edhed by M. G. Velarde and C. I. Christor

Volume 6: Dynamics of Nonlinear and Disondered Systems

Edited by $G$. Martinoz-Makbr and T. H. Saligman 


\section{DYNAMICS OF NONLINEAR AND DISORDERED SYSTEMS}

edited by

G. Martínez-Mekler \& T. H. Seligman UNAM, MeXICO 


\section{Published by}

Worid Scientific Publishing Co. Pre. Lud.

PO Box 128. Farrer Road, Singapore 9128

USA office: Suite 1B, 1060 Main Street, River Edge, NJ 07661

UK office: 57 Shelton Street, Covent Ganden, London WC2H 9HE

\section{DYNAMICS OF NONLINEAR AND DISORDERED SYSTEMS}

Copyright 01995 by World Scientific Publishing Co. Pre. Led.

All rights reserved. This book or parts thereof, may not we reproduced in any form or by any means, electronic or mechanical, including photocopying, recording or any information storage and retrieval system now known or to be invented, without written permission from the Publisher.

For photocopying of material in this volume, please pay a copying fee through the Copyright Clearance Center, Inc., 27 Congress Street, Salem, MA 01970. USA.

ISBN $981-02-2280-7$

Printod in Singapore. 


\section{PREFACE}

The genesis of this book goes back to the summer of 1992 when the Latin-American School of Physics took place in México City on the subject of Dynamics of Nonlinear and Disordered Systems. Our aim on that occasion was to give an overview of selected topics on the cutting edge of nonlinear science research, striking a balance between theory and experiment, applied and basic research, quantum and classical systems. Encouraged by the interest and enthusiasm displayed during the three week School by the hundred or so School attendants (mainly $\mathrm{Ph} \mathrm{D}$ students and postdocs from the subcontinent), we decided to share the effort invested by the lecturers with a wider audience by inviting them to make a contribution to a book. Our proposal was to go beyond the usual proceedings-type volume by asking the authors to write a polished, pedagogical review of their research area including some of their own recent findings. Fortunately, most lecturers decided to participate in the project, submitting in the majority of cases a 1994 updated contribution with the above characteristics.

The book consists of two introductory presentations and six advanced research chapters. The tutorial material deals with general concepts of dynamical systems and fluid dynamics. The first of these has the purpose of conveying to non-mathematicians a mathematician's outlook on some of the main results of the qualitative study of hyperbolic dynamics. The authors X. Gómez-Mont and L. Ortiz-Bobadilla emphasize central issues in an accessible manner. The study of continuous systems eventually leads to discrete mappings entering the realm of chaos. The role of structural stability is dealt with in depth including a discussion of the present day status of the program set by S. Smale regarding the ubiquity of hyperbolic 
systems. A construction of considerable pedagogical merit of a persistent chaotic dynamical system originally due to Professor Y. S. Ilyashenko is included as well.

The second general background contribution deals with fluid dynamics. R. Peralta-Fabi gives a personal overview emphasizing concepts. The presentation "flows" smoothly. Constitutive and Navier-Stokes equations are derived, and microscopic foundations as well as exact viscous flow solutions are presented. The special role of dimensional analysis is pointed out and a discussion on stability and turbulence is forwarded. A section related to recent theoretical and experimental work carried out at the authors' laboratory on avalanches in granular material ends this chapter.

A comprehensive up to date account of the development of theoretical and experimental studies of parametric instabilities is the content of the contribution of S. Fauve. The presentation relies on selected illustrative examples ranging from a pendulum with a vibrating support to the analysis of the Faraday instability. Parametric resonance, Floquet theory, stability analysis in the presence of dissipation, all come into the study of the behavior of nonlinear waves in dispersive media. Some recent experimental work performed by the author and coworkers on pattern selection in fluid mechanics is presented, in particular, the emergence of quasicrystalline structures is exhibited.

The contribution of $\mathbf{R}$. Lima is of a more formal nature. In the search for the characterization of the complex evolution of extended systems, where the spatial and temporal properties are tightly interdependent, he introduces an "orthogonal decomposition" in the function space describing the system. The goal is to obtain a framework defined on a lower dimensional description (number of independent degrees of freedom) where the study of bifurcations and the location of attractors a is more amiable task.

In the presentation of $F$. Leyvraz some of the intricacies of reaction kinetics are explored under the light of scaling theories. The main phenomena considered are related to aggregation. Special care is given to clarify the limits of the validity of mean-field approximations frequently used. Again in this case the understanding of conceptual points is achieved via concrete examples. The processes under consideration are stochastic leading to master equations for their description. The concepts developed for the aggregation problems are extended to the study of reaction-diffusion wavefronts. Exactly soluble models are introduced as a guide to the understanding of 
more realistic situations, in particular, the build up of correlations that invalidate mean-field approaches due to transport mechanisms is pointed out.

The work of $R$. Barrio sets up a formalism for the analysis of structural and vibrational properties of solids adequate for dealing with crystalline, quasicrystalline and disordered instances. The geometrical problem is addressed in terms of nonlinear mappings related to the probability of encountering specified agglomerations of basic units. These agglomerations produce the intermediate range order characteristic of disordered materials. The stability properties of the mappings are indicative of the emergence of crystalline or amorphous states. The method is extended to study structural changes due to the addition of modifiers (metal oxides) to glasses, as well as to situations with quasicrystalline symmetries. Finally, under the same perspective, the dynamics of growth of solids is studied with mappings built via an Ising model simile. Both methodologically and conceptually the research presented here is a true melting pot: statistical mechanics, dynamical systems theory and gauge theory, all come into play.

An introductory presentation of some of the basic considerations for the design of particle accelerators is given by A. Antillón. A nonlinear stability analysis of the transverse motion of the particle beam provides criteria to avoid resonant behaviors.

The presentation of $\mathrm{H}$. Weidenmüller closes in a sense the circle. By asking for quantum (or wave) signatures of classical (or ray) chaotic behavior we return to linear systems. Random matrix theory is shown to be the key for the connection of chaotic macroscopic dynamics and the corresponding linear microscopic wave equation. A wealth of examples such as microwave cavities, nuclei, molecules are discussed. The exposition continues to mesoscopic systems where quantum effects dominate the behavior of man made devices. Despite of the fact that this presentation is a little older than the other ones, it still gives an up to date overview of a field dominated by the author's own world to a large extent.

A nontrivial interrelation between the different topics becomes apparent through out the book as an indication of the underlying unity and genericity of nonlinear phenomena. For example the subject of quasicrystals appears in the remarkable fluid experiments of Fauve as well as in the solid growth problems addressed by by Barrio. The introductory material presented by Gómez-Mont and Ortiz-Bobadilla finds its way in the context 
of hydrodynamics (see Peralta), amorphous materials (see Barrio), spacetime pattern formation (see Lima), quantum chaos (see Wiedenmüller), high energy particle beams (see Antillón), fluid instabilities (see Fauve). The stochastic nature of some of the systems under consideration leads to the common use of master equations, for example, in the azgregation problems addresed by Leyvraz and the sand pile studies presented by Peralta. Scattering experiments also emerge as commonplace in the solids, fluids, aggregates as well as the quantum systems. Another unifying thread is the realization that most of the material in this volume deals with nonhomogeneous extended systems far from equilibrium.

We hope that this book will appeal to the curiasity of readers working in different problems of nonlinear science enticing them to explore other areas of this field.

Finally we would like to express our gratitude to Antonio GarciaZenteno for his help in the production of this book.

Gustavo Martínez-Mekler,

T. H. Seligman,

UNAM, Mexico City, 1995. 


\section{CONTENTS}

Preface . . . . . . . . . . . . . . . . v

1. Order and Chaos in Dynamical Systems . . . . . . . . . 1 Xavier Gómez-Mont and Laura Ortiz-Bobadilla

2. Selected Topics in Fluid Dynamics . . . . . . . . . 25 Ramón Peralta-Fabi

3. Parametric Instabilities . . . . . . . . . . . . . 67 Stephan Fauve

4. Odds and Ends in Space-Time Dynamical Systems . . . 117 Ricardo Lima

5. Scaling Theory of Aggregation . . . . . . . . . . . . . . 141 François Leyvraz

6. Disorder in Solids . . . . . . . . . . . . . . . . . . . 169 Rafael Barrio

7. Stability in Particle Beams . . . . . . . . . . . . . . . 185 Armando Antillón

8. Stochastic Scattering Theory or Random-Matrix Models for Fluctuations in Microscopic and Mesoscopic Systems . . 197 Hans A. Weidenmüller 